\title{
Semantic Content of the Tokens Risk, Risky and High Risk in Modern Russian
}

\section{Ivanova Nelya Stefanova ${ }^{1}$}

Professor of Assen Zlatarov University, Burgas, Bulgaria.

(date of receiving: December, 2019; date of acceptance: April, 2020)

\begin{abstract}
The presence of certain stable cultural and national representations, some "mental pictures" similar to ours or different from them, is especially pronounced in the classroom when learning a foreign language. Without direct contact with native speakers, the source of knowledge about their mentality, national character and cultural scenarios of behavior is the studied foreign language. Risk is considered the basic concept of the universal picture of the world. It is analyzed as one of the main components of a person's ideas about the world, about the laws of its existence and survival in it. There is no person who would not risk it. Making any decision is already a risk. The cognitive risk perception scheme is based on the unity of opposite meanings: potential opportunity (threat) - its realization (danger); the need for action — inaction (and the hope of a fluke); positive development (chance, success) - negative development (failure). In the report, we consider the semantic transformations of the risk token and its 3 derivatives in modern Russian.
\end{abstract}

Keywords: Risk, Conceptualization, Risky, Modern Russian Language.

1.Email:nelya_ivanova@yahoo.com 


\title{
Семантический потенциал лексем рисковый, рисковой и рискованный в современном русском языке
}

\author{
Иванова Неля Стефанова ${ }^{1}$ \\ Профессор, Университет им. Асена Златаров, \\ Бургас, Болгария.
}

(дата получения: декабрь 2019 г.; дата принятия: апрель 2020 г.)

\begin{abstract}
Аннотация
Наличие определенных устойчивых культурно-национальных представлений, своеобразных «ментальных картинок», похожих на наши или отличных от них, особенно ярко проявляется в учебной аудитории при изучении иностранного языка. Без непосредственного контакта с носителями языка источником знаний об их менталитете, национальном характере и культурных сценариях поведения является изучаемый иностранный язык. Риск считается базовым концептом общечеловеческой картины мира. Он рассматривается как одно из основных составляющих представлений человека о мире, о законах его существования и выживания в нем. Нет человека, который бы не рисковал. Принятие любого решения - это уже риск. Когнитивная схема восприятия риска строится на единстве противоположных смыслов: потенциальная возможность (угроза) - ее реализация (опасность); необходимость действия - бездействие (и надежда на счастливую случайность); положительное развитие (шанс, успех) - негативное развитие (неудача, неуспех). В докладе мы рассматриваем семантические преобразования лексемы риск и ее производных рисковый, рисковой и рискованныци, которые отражают общие тенденции в современном русском языке.
\end{abstract}

Ключевые слова: Риск, Концептуализация, Русский Язык, Рисковый, Рискованный.

1. E-mail: nelya_ivanova@yahoo.com 


\section{Введение}

Современное языкознание активно разрабатывает тематику о взаимосвязанном пространстве человека, языка, общества, культуры в самых разнообразных форматах, способствующих выявлению когнитивных механизмов восприятия и оценки действительности. В своем исследовании «Сопоставление культур через посредство лексики и прагматики» А. Вежбицкая вводит понятие «культурного сценария», целью которого автор видит не в описании, как ведут себя все члены данного общества, а «четко сформулировать те нормы, с которыми люди знакомы (на сознательном, полусознательном и подсознательном уровне) и которые являются эталонными фреймами для данного языкового коллектива (вне зависимости от того, следуют им или обходят их члены этого коллектива)». (Вежбицкая 1999. 653) Своеобразная матрица познавательных схем (фреймов), «наиболее распространенных в диахронном (продолжающемся во многих поколениях) сообществе (вместе с символами и мировоззренческими установками)», согласно Н.С. Розову, составляют национальный менталитет. (Розов 2010. 62)

Наличие определенных устойчивых культурно-национальных представлений, похожих на наши или отличных от них, особенно ярко проявляется в учебной аудитории при изучении иностранного языка. Без непосредственного контакта с носителями языка источником знаний об их менталитете, национальном характере и культурных сценариях поведения является изучаемый иностранный язык.

Конечно, когда речь идет о русском и болгарском языках, то квалификация «иностранные языки» кажется преувеличенной ввиду их общих славянских корней. Но этот факт делает анализ еще более оправданным и необходимым. Является ли близкородственность языков основанием для выводов о схожести в восприятии действительности?

В поисках ответа на вопросы о культурно-национальных представлениях, отраженных в языке, многие лингвисты сегодня исследуют процессы 
категоризации и концептуализации, изучают концепт как единицу сознания и глобальную единицу мышления человека. В болгарском языкознании в последнее время появилось много трудов, посвященных исследованию разнообразных концептов, таких как время, пространство и движение /М. Вътова/, возраст /Д. Митев/, свобода /Г. Йорданова/, служить / Цв. Георгиева/, молчание /Ст. Петкова-Калева/, истина и ложь /Д. Илиева/, счастье, время, правда/Ю. Чакърова/, успех/Н. Иванова/ и мн. др.

Цель настоящей статьи связана с анализом концепта риск, который считается одним из базовых концептов общечеловеческой картины мира, связанных с представлениями людей об опасности, с законами их существования и выживания в мире (Ефимова 2008. 138). Конкретным поводом для написания этой статьи являются прилагательные рисковый, рисковой и рискованный. Трудности в их употреблении есть даже у болгар, изучающих русский язык (в учебной аудитории с которыми мы работаем), несмотря на близость языков, тем более для англоязычных носителей, так как этим двум лексемам соответствует в английском только одна - risky.

Лексемы рисковый и рискованный являются производными одного и того же существительного - риск, и словари конструируют их семантическое пространство логично по отношению производящей лексемы: 'относящиеся к риску'.

Но что такое риск? И каким образом в производных прилагательных отражается его суть?

\section{Основная часть}

Риск - понятие, известное всем людям. Н.Н. Ефимова пишет, что „понимание и предвидение поведения людей в большинстве случаев требует понимания понятия риск и его сущности” и это так, потому что риск связан с принятием решений, с определением стратегий поведения (Ефимова 2008. 
134). Специальное внимание этим вопросам уделяется в психологии, где ситуации, связанные с риском и его последствиями, называют „драмой необходимости выбора" (Илиев 2004. 12).

Когнитивная схема восприятия риска строится на единстве противоположных смыслов: это потенциальная возможность и ее реализация (опасность, угроза); необходимость действия и положительное развитие ситуации (шанс, успех) или негативное развитие ситуации (неудача, неуспех, провал).

Ситуация риска требует особой активности со стороны субъекта - требует и его предварительной оценки, и его действия. Как указывает В. Илиев, „сущность риска - это своеобразный фильтр, который человек накладывает на информацию о мире и на свои действия в нем, оценивая последствия для себя как угроза или польза. Или, более обобщенно, как альтернатива” (Там же. 30).

В лингвистике дефинирование любого концепта начинается с определения его понятийного ядра, а это означает анализ семантики ключевого слова.

Толковые словари конструируют смысловое пространство лексемы риск в русском языке следующим образом:

В русском языке: Риск 1. Возможность опасности, неудачи. Идти на риск. Без всякого риска. С риском для жизни. Группа риска (группа лиц наиболее подверженных риску). 2. Действие наудачу в надежде на счастливый исход. На свой риск. На свой страх и риск действовать, поступать (полностью на свою ответственность). Риск - благородное дело разг., шутл. - можно, стоит рискнуть, попробовать; Рисковать - 1. Действовать, зная об имеющемся риске, опасности. Не боится р. кто-н. 2. Кем-чем подвергать кого-что-н. риску (в 1 знач.) р. Своим здоровьем. 3. С неопр. Подвергаться риску, ставить себя перед возможной неприятностью. Рискуем опоздать. (Ожегов С.И. и Шведова Н.Ю. Толковый словарь русского языка: 80000 слов и фразеологических выражений / Российская академия наук. Институт русского языка им. В.В. Виноградова. - 4-е изд., дополненное. - М.: 
Азбуковник, 1999. - 944 с.); для сравнения и в болгарском языке: Риск - 1. Възможна опасност. Излага се на риск. 2. Действие наслука. Ще го направя на риск. 3. Възможна загуба при търговска дейност. Ще делим риска поравно. Рискувам - св. и несв. прх. и непр. Излагам (се) на риск, предприемам нещо, свързано с риск. Не смея да рискувам. Рискувах живота си. (Български тълковен речник 2002. 843)

Общими в концептуализации риска в обоих языках, согласно словарным определениям, являются потенциальность его возникновения - 'возможная опасность', възможна опасност (несомненно этимология самого слова, восходящего к древнегреческому 'risikon', 'отвесная скала', накладывает отпечаток на его осмысление, об этом Ефимова 2008) и действие субъекта в условиях неопределенности - ‘ействовать наудачу', действие наслука.

В русских словарных статьях и в проведенной анкете с носителями русского языка больше оценочных определений ситуации риска: риск благородное дело; риск оправданный, естественный, логичный, основной, существенный.

В словарной статье на болгарском языке не присутствуют оценочные элементы ситуации риска - не упомянута возможность положительного исхода ситуации риска. Но в анкетах все опрашиваемые болгарские студенты (100 человек) ответили, что риск для них положительное явление и когда они предпринимали решительные действия в неопределенной ситуации (58\%), то получали пользу для себя.

Идиоматичные выражения с лексемой риск в болгарском языке отражают прагматическую установку вовлеченного субъекта и акцентируют конкретное измерение пользы: риск печели, риск губи; да си разделим риска поравно. Дефинирование риска в проведенной анкете с информантами связано преимущественно с количественной шкалой минимальный - максимальный риск (85\%). 
В русском языке устойчивое выражение 'действовать на свой страх $и$ риск' отражает рефлексию субъекта по отношению своих самостоятельных решительных действий в условиях неопределенности: примечателен тот факт, что расширяется семантическое пространство концепта риск, субъект включает еще один параметр рефлексии - оценку своего душевного переживания.

Анализ публицистических текстов, в которых употреблены предикатные словосочетания с лексемой риск, показывает метафорические представления и русских, и болгар о риске как о находящемся рядом с субъектом, но скрывающемся, сопутствующем или угрожающем существе или сущности, которые нужно открыть, атаковать, побеждать, провоцировать или превозмогать, избегать, отклонять, причем очень часто лексема риск употребляется в множественном числе, чем достигается более высокая степень экспрессии в импликации опасности:

„Мажоритарното гласуване крие огромни рискове /p. Мажоритарный вот скрывает огромные риски; високата температура крие рискове за здравето /p. Высокая температура скрывает риски для здоровья; Бежанската вълна носи големи рискове /p. Волна беженцев несет большие риски; Президентьт свиква КСНС за геополитическите промени и за рисковете пред България /p. Президент сзывает КСНС по вопросам о геополитических изменениях и рисках перед Болгарией, Качеството на човека да превъзмогва беди и рискове $/ p$. Качество человека превозмогать беды и риски; По възможност избягвайте рисковете /p. По возможности избегайте рисков; Возрастные особенности способны провоцировать риск раннего приобщения к алкоголю и курению; Риск не всегда ведет к проблемам и опасностям; Не бойтесь идти на риск!; Только в этом случае социальная выгода от наказания начинает перевешивать риск и расходы и др.

Персонификация риска как гостя, которого принимаем, представляет риск как позитивное явление: „Приемам възхитителния риск да бъда жив! /p. 
„Принимаю восхитительный риск быть живыми!“ (Христо Фотев, Собрание сочинений, 1998. 156); „Свободата е отговорност, но тя е и приемане на риск” /p. „Свобода - это ответственность, но она означает и принятие риска“; „Енергичен, обича да доминира и приема риск”/р. Энергичныий, любит доминировать и принимает риск; „Решение принять риск привело к успеху” и др., в которых лексема риск употребляется в единственном числе.

Совсем иную концептуальную модель имеет риск в деловой сфере (и в русском, и в болгарском языках): риск измеряют в точных процентах (35\% риска означает исчисление негативных последствий развития определенной системы).

Кроме того в экономике риск/риски классифицируют: известны ретроспективные, текущце $и$ перспективные риски; политические $u$ экономические /коммерческие/; внешние $и$ внутренние; чистые $и$ спекулятивные; производственные, финансовые, страховые; организационные, рыночные, кредитные, юридические; природные и технические; объективные и субъективные; риск взвешивают; риск смягчают, риск трансферируют, риском управляют.

В деловой сфере риск имеет только одно измерение - измерение негативного исхода.

На наших глазах слово риски из финансово-экономического и юридического дискурса переходит в публицистику и разговорную речь, обретая контекстную нюансировку. В статье модного российского прозаика, поэта и публициста Дм. Быкова «Валить из страны?» читаем: «В России больше всего ценится полупризнанный гений, неофициальный авторитет. А влезть на вершину пирамиды, от которой ничего не зависит (кроме права безнаказанно тырить большие деньги, но ведь у этого занятия свои риски), - не знаю, зачем это нужно?» (Быков 2011. 44). «В управлении рисками я эксперт» - это признание вынесено в заглавие статьи о лидере культовой «рокпопсовой» группы «Мумий Тролль» Илье Лагутенко. В обширном 
интервью с ним выделена с помощью дополнительной врезки в текст только одна, весьма характерная фраза музыканта: «Главное - донести до ребят очевидную, казалось бы, мысль: в любом начинании риск есть уже изначально, но, если научиться этим риском управлять, - можно достичь гораздо большего, чем планировал» (Лагутенко 2011. 6).

Благодаря концепту «риск» в русскоязычной среде проходят различные стадии адаптации англицизмы, обозначающие новые для российской действительности и ментальности явления - трудно осваиваемые (согласно мнению носителей русского языка), малопонятные и небезопасные. Так, Г.Н. Скляревская классифицирует слово венчурный исключительно как профессионализм: «Венчурный. Фин. Направленный на финансирование новых неапробированных идей, проектов и т.п. и связанный с риском». В то же время В.Т. Пономарёв в сегменте профессионализмов уже выстраивает синонимический ряд, что свидетельствует о своеобразном «обрусении» заимствования: «Венчурный (рисковый) бизнес бизн. - Основная форма технологических нововведений» (Пономарёв 1996. 198).

Процесс адаптации при соотнесённости с концептом «риск» наблюдаем также у другого англицизма: «На самом же деле слово «дауншифтинг» означает скорее историю отказа от успеха в его общепринятом понимании. Ведь готовность пойти на риск, отказавшись от высокооплачиваемой работы и положения в обществе ради воплощения своих идеалов или чувства свободы, удовольствие не для каждого» (Титова 2011. 157).

Этому понятию посвящены статьи в болгарской социологии: „Дауншифтингът е съвременен феномен, засягащ все повече сфери на личния и професионален живот. На фона на материалистичните представи за добър живот, доброволното отказване от висок доход, кариерно преуспяване и постигане на финансов успех в името на личностното развитие и свобода, на пръв поглед изглежда немислимо и алогично. Въпреки това, в редица изследвания могат да бъдат открити индикации за фундаментална промяна 
към намаляване на оборотите на забързаното ежедневие, откъсване от корпоративната среда и желание за по-малко време, прекарано на работното място Докато безбожно богатите строят цели заградени селища, където пиле не може да прехвръкне, замъци, хотели, нови строителни фирми и други подобни, предимно обслужващи строителството и хотелиерството предприятия, в известен смисъл те също се завръщат към природосъобразен живот, но...в пълния му лукс. /p. «Дауншифтинг является современным феноменом, охватывающим все больше сфер личной и профессиональной жизни. На фоне материалистических представлений о хорошей жизни, добровольный отказ от высокого дохода, карьерного преуспевания и достижения финансового успеха во имя личностного развития и свободы, на первый взгляд кажется немыслимым и алогичным. Несмотря на это, в ряде исследований могут быть открыты индикации о фундаментальном изменении в сторону замедления оборотов ежедневия, отрыва от корпоративной среды и желания проводить меньше времени на рабочем месте. Пока очень богатые строят целые огражденные селения, куда никто не может проникнуть, замки, отели, новые строительные фирмы и другие подобные, преимущественно обслуживающие строительство и гостиничный бизнес предприятия, в некотором смысле они тоже возвращаются к природосообразному стилю жизни, но ... в полном люксе.» (Бъзовска 2016. 1169, пер. с болг. Н.И.)

В комментариях этого термина представлена также житейская философия, которая имеет специфическую „болгарскую окраску”: „Дауншифтинг! Защо не?! Интересен български вариант?! Защото, всъщност, новобогаташите също не се подчиняват на никого и не спазват правила. Най-главното е, че се отдават на себе си, а някои и на семействата си /p. „Дауншифтинг! Почему нет?! Интересный болгарский вариант?! Потому что, в сущности, новоиспеченные богачи тоже не подчиняются никому и не соблюдают правил. Самое главное то, что они посвящают себя себе и своей семье ...“ (Милева 2011, пер. с болг. Н. И.) 
Широко распространена в живой русской речи шутливая пословица «Кто не рискует, тот не пьёт шампанское / шампанского». Её значение приравнивается к значению пословицы «Была - не была» (Химик 2004. 701). Популярность этой пословицы в современном русскоязычном фольклоре доказывают многочисленные остроумные, а порой и вульгарные, переделки: «Кто не рискует, того не хоронят в гробу из красного дерева», «Кто не рискует, тот не пьёт валокордин», «Кто не рискует, тот не пьёт валерианку», «Кто не рискует, тот не пьёт шампанского. А кто рискует, тот вообще не пьёт» (Мокиенко, Вальтер 2008. 384).

На наш взгляд, два паронима - рисковОй и рискОвый возникли в речи бизнеса.

Сочетаемость прилагательного рисковОй 'основанный на риске' рисковОй менеджмент, сделка, премия, страховка, надбавка, случай, дорога, приключение - указывает на аттрибуцию неодушевленных объектов, в то время как рискОвый проявляет семантическую избирательность только по отношению одушевленных субъектов: рисковый парень, команда, имея значение 'готовый на риск'.

С лексемой рискОвый с пометой простореч. (рискОвое дело, рискОвый парень) в толковых словарях: С.И. Ожегова и Н.Ю. Шведовой; в Словаре под ред. А.П. Евгеньевой (Словарь русского языка: в 4-х тт. / АН СССР, Ин-т рус. яз.; под ред. А.П. Евгеньевой. - 2-е изд., испр. и доп. - М.: Русский язык, 1981 - 1984. Т.: 3. П - Р. 1983. - 752 с.); ненормативной лексики русского языка Д.И. Квеселевича (Квеселевич Д.И. Толковый словарь ненормативной лексики русского языка / Д.И. Квеселевич. - М.: ООО «Издательство Астрель»: ООО «Издательство АСТ», 2003. - 1021 с.) начинает коррелировать лексема безрИсковый с пометой коммери.: безрИсковая финансовая деятельность, безрИсковая доходность (в словаре под ред. Г.Н. Скляревской). 
Прилагательное рискованный входит в один синонимический ряд с прилагательным рисковОй, имея значение 'содержащий риск', 'опасный', 'заведомо опасный' и сочетаясь с неодушевленными существительными рискованный капитал, бизнес, дело, поступок, шаг, предприятие.

Словари (Ожегов С.И. и Шведова Н.Ю. Толковый словарь русского языка: 80000 слов и фразеологических выражений / Российская академия наук. Институт русского языка им. В.В. Виноградова. - 4-е изд., дополненное. - М.: Азбуковник, 1999. - 944 с.) также содержат информацию об употреблении этого слова в значении 'не совсем приличный', 'двусмысленный': рискованный туалет, иутки, острота, выражение.

Сегодня за счет расширения сочетаемости этого прилагательного (мы заметили только примеры сочетаемости со словами женщцна и девушка) можно наблюдать образование нового значения: 'смелый', 'любящий риск', 'готовый на риск', 'стремящийся к риску’: „, - Вы рискованная женщина! улыбнулся ей Эдди. - Нет, я просто авантюрист по духу!” (Гуртрих 2017. 82); рискованная девушка /о девушке, делающей опасные селфи на большой высоте/; „Восхитительное длинное голубое платье из шелка при каждом шаге играло, словно легкая прибрежная волна при спокойном бризе, и открывало внизу изящные, под цвет платья, туфли на шпильках, стройные ноги чуть выше восковых икр, а наверху то, что могла открыть самая рискованная женщина”, Никонов 2017. 67)

\section{Заключение}

Интерес к взаимосвязанному пространству человека, общества и культуры в самых разнообразных форматах, который характеризует современную науку, способствует выявлению когнитивных механизмов восприятия и оценки действительности. Исследование процессов категоризации и концептуализации, анализ концептов как единиц сознания человека очень последовательно можно проследить в работах современных лингвистов. 
Стремление узнать больше о многоизмерном культурном, общественном и личном пространстве человека логично дополняется исследованием его языка, позволяющем проникнуть в сферу ментальности и раскрывающем способ членения мира в той или иной культуре.

Проведение сопоставительных ракурсов с другими языками является отличительной характеристикой многих из этих трудов, что позволяет получить информацию об универсальном и специфическом в картинах мира различных народов, об их мироощущении, их ментальности. В таком плане проведено и наше исследование, имеющее целью проанализировать вербальную сферу концепта риск.

Исследуя семантику лексемы риск и ее производных прилагательных рисковыцй, рисковой и рискованный, можно проследить семантические преобразования этих лексем, которые являются совсем новым фактом в современном русском языке.

Построение синонимичных рядов с этими прилагательными может дать информацию о прагматических установках говорящих и поможет изучающим русский язык понять разницу в их сочетаемости и значении.

Фактор риска, фактор случайного и неопределенного, еще со времен древних цивилизаций был фактором важным в жизни человека, общества, культуры. В языке он имеет свои конкретные координаты, провоцируя интерпретацию и активные действия людей, о чем свидетельствует сам язык.

\section{Литература}

1- Бъзовска Б. (2016). Дауншифтинг като доброволна промяна в кариерното развитие. Причини за възникване и връзка с благополучието // Лидерство и организационно развитие. София: Изд-во Университетско издателство «Св. Кл. Охридски».

2- Быков Д. (2011). Валить из страны?? «Аргументы и факты». № 44.

3- Вежбицкая А. (1999) Семантические универсалии и описание языков. -М.: Изд-во «Языки русской культуры». 
4- Гуртрих М. (2005). Формула любви: https://books.google.bg/books, Режим доступа: 20 .10. 2018.

5- Ефимова Н.Н. (2008). Риск как репрезентативный кониепт общзечеловеческой картины мира (на примере концептуализации в картине мира британцев) // Этносемиометрия ценностных смыслов, Иркутск: Изд-во «ИГЛУ» - С. $134-$ 156.

6- Илиев В. (2004). Риск и общуване, София: Изд-во «Леге Артис».

7- Лагутенко И. (2011). В управлении рисками я эксперт. Журнал Обучение \& Карьера» - № 6 .

8- Милева П. (2011). Кариерата - инвестициия в жизнената стратегия: kariernainvesticya.blogspot.com/2011/11/. Режим доступа: 15. 11. 2018.

9- Мокиенко В.М., Вальтер Х. (2008) Прикольный словарь (антипословиць и антиафоризмы). -М.: Изд-во «ОЛМА Медиа Групп». - 384 с.

10- Никонов А. (2016) Я иду к тебе, сынок (https://books.google.bg/books?isbn= 5040112785, 2017). Режим доступа: 29 03. 2019.

11- Пономарёв В.Т. (1996) Бизнес-сленг для «новых русских». - Донецк: Изд-во «Сталкер».

12- Розов Н.С. (2010). Динамическая концепция менталитета // Журнал Идеи и идеалы. №1(3), т.1. С.60-79

13- Титова И. (2011) Реальный дауншифтинг // Газета «Московские новости». 2011. № 157).

14- Толковый словарь современного русского языка. Языковые изменения конияа ХХ столетия. (2001) Под ред. Г.Н. Скляревской. -М: Изд-во „Аст“.

15- Фотев Хр. (1998). Събрани съчинения. Т. 1. Поезия. София: Изд-во «Казански».

16- Химик В.В. (2004). Большой словарь русской разговорной экспрессивной речи. Под ред. Химик В.В. -СПб.: Изд-во: «Норинт»,. -768 с.

\section{Bibliography}

1- B\#zovska B. (2016). Daunshifting kato dobrovolna promjana v kariernoto razvitie. Prichini za v\#znikvane $i$ vr\#zka s blagopoluchieto // Liderstvo i organizacionno razvitie. Sofija: Izd-vo Universitetsko izdatelstvo «Sv. Kl. Ohridski».

2- Bykov D. (2011). Valit' iz strany? «Argumenty i fakty». № 44.

3- Vezhbickaja A. (1999) Semanticheskie universalii i opisanie jazykov. -M: Izd-vo «Jazyki russkoj kul'tury». 
4- Gurtrih M. (2005). Formula ljubvi: https://books.google.bg/books, Rezhim dostupa: 20 .10. 2018.

5- Efimova N.N. (2008). Risk kak reprezentativnyj koncept obshhechelovecheskoj kartiny mira (na primere konceptualizacii $v$ kartine mira britancev) // Jetnosemiometrija cennostnyh smyslov, Irkutsk: Izd-vo «IGLU» - S. 134-156.

6- Iliev V. (2004). Risk i obshhuvane, Sofija: Izd-vo «Lege Artis».

7- Lagutenko I. (2011). V upravlenii riskami ja jekspert. Zhurnal Obuchenie \& Kar'era» - № 6.

8- Mileva P. (2011). Karierata - investicija v zhiznenata strategija: kariernainvesticya.blogspot.com/2011/11/. Rezhim dostupa: 15. 11. 2018.

9- Mokienko V.M., Val'ter H. (2008) Prikol'nyj slovar' (antiposlovicy i antiaforizmy). -M.: Izd-vo «OLMA Media Grupp». - $384 \mathrm{~s}$.

10- Nikonov A. (2016) Ja idu $k$ tebe, synok (https://books.google.bg/books?isbn= 5040112785, 2017). Rezhim dostupa: 29 03. 2019.

11- Ponomarjov V.T. (1996) Biznes-sleng dlja «novyh russkih». Doneck: Izd-vo «Stalker».

12- Rozov N.S. (2010). Dinamicheskaja koncepcija mentaliteta // Zhurnal Idei i idealy. №1(3), t.1. S.60-79

13- Titova I. (2011) Real'nyj daunshifting // Gazeta «Moskovskie novosti». - 2011. № 157).

14- Tolkovyj slovar' sovremennogo russkogo jazyka. Jazykovye izmenenija konca XX stoletija. (2001) Pod red. G.N. Skljarevskoj. -M: Izd-vo „Ast““.

15- Fotev Hr. (1998). S\#brani s\#chinenija. T. 1. Poezija. Sofija: Izd-vo «Kazanski».

16- Himik V.V. (2004). Bol'shoj slovar' russkoj razgovornoj jekspressivnoj rechi. Pod red. Himik V.V. -SPb.: Izd-vo: «Norint»,. - 768 s.

\section{HOW TO CITE THIS ARTICLE}

Иванова Н. C. (2020). Semantic Content of the Tokens Risk, Risky and High Risk in Modern Russian. Issledovatel'skiy Zhurnal Russkogo Yazyka i Literatury, 8(2), 35-50.

DOI: 10.29252 iarll.16.35

URL: http://journaliarll.ir/index.php/iarll/article/view/126

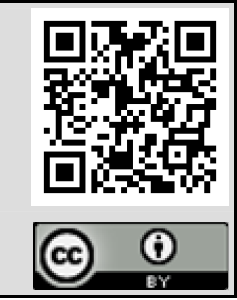




\section{بررسى ظرفيت معنايى وازْهاى рисковый (خطريذير)، рисковой (خطرناك)} و рискованный (برخطر) در زبان روسى معاصر

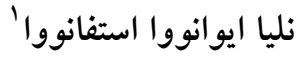

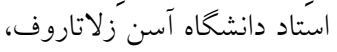

$$
\begin{aligned}
& \text { بور كاس، بلَغارستان. }
\end{aligned}
$$

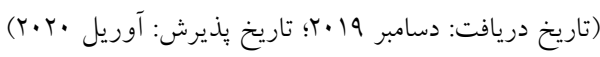

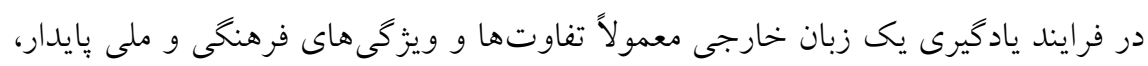

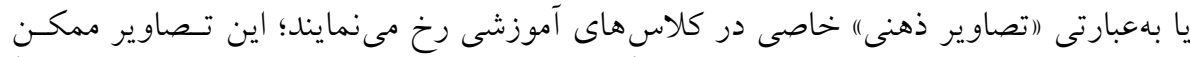

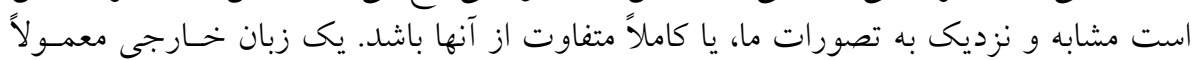

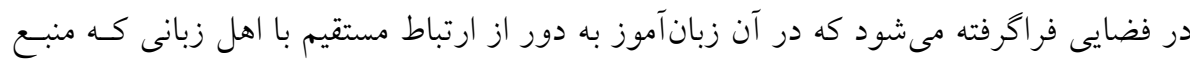

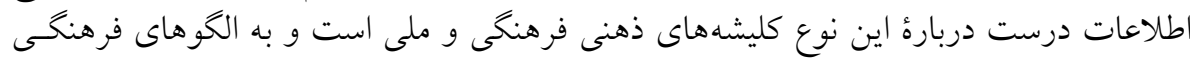

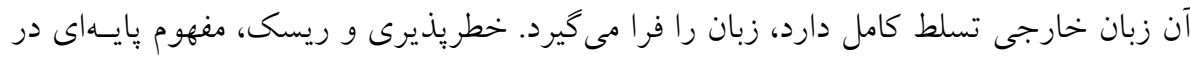

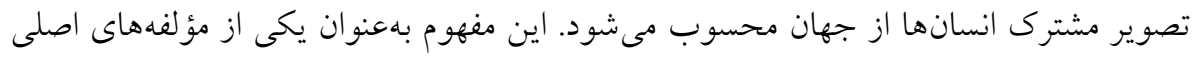

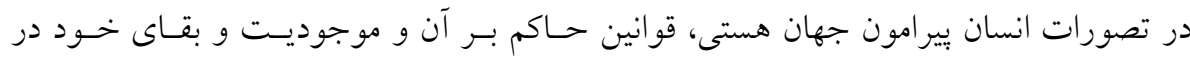

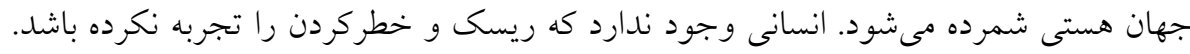

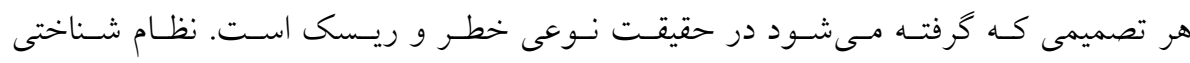

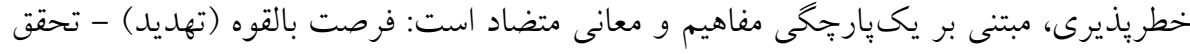

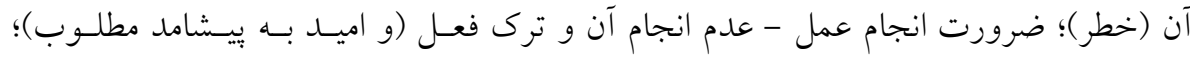

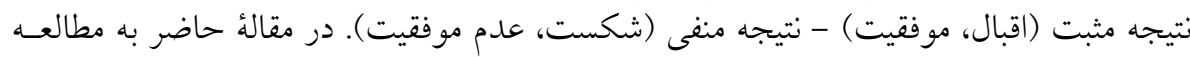

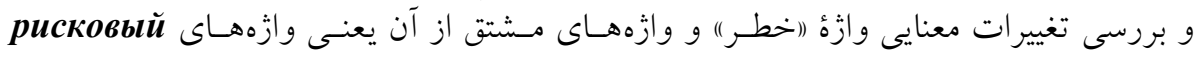

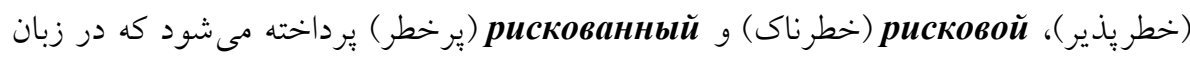

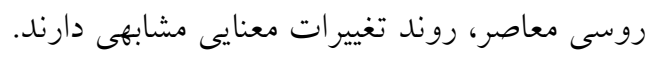

$$
\text { وازگًان كليدى: خطر (ريسك)، تصويرسازى، زبان روسى، خطريذير، برخطر. }
$$

